\title{
Review
}

\section{Monitoring beaked redfish (Sebastes mentella) in the North Atlantic, current challenges and future prospects}

\author{
Benjamin PlAnQUE ${ }^{1}$, Kristján Kristinsson ${ }^{2, a}$, Alexey ASTAKHOV ${ }^{3}$, Matthias BeRnReUTHER ${ }^{4}$, \\ Eckhard BETHKE ${ }^{4}$, Konstantin DREVETNYAK ${ }^{3}$, Kjell NEDREAAS ${ }^{5}$, Jákup REINERT ${ }^{6}$, Alexey RoLSKIY ${ }^{3}$, \\ Thorsteinn SIGURĐSSON ${ }^{2}$ and Christoph STRANSKY ${ }^{4}$ \\ 1 Institute of Marine Research, PO Box 6404, 9294 Troms $\varnothing$, Norway \\ 2 Marine Research Institute, Skúlagata 4, PO Box 1390, 121 Reykjavík, Iceland \\ 3 Knipovich Polar Research Institute of Marine Fisheries and Oceanography (PINRO), 6 Knipovich Street, 183038 Murmansk, \\ Russian Federation \\ 4 Thünen Institute of Sea Fisheries, Palmaille 9, 22767 Hamburg, Germany \\ 5 Institute of Marine Research, PO Box 1870 Nordnes, 5817 Bergen, Norway \\ ${ }^{6}$ Faroe Marine Research Institute, Nóatún, PO Box 3051, 110 Tórshavn, Faroe Islands
}

Received 2 January 2013; Accepted 3 June 2013

\begin{abstract}
Beaked redfish inhabits North Atlantic waters in the depth range 100-950 m, over the continental shelf, slope and the open ocean. Individuals can live demersal or pelagic, at various stages of their life cycle. The geographical distribution of the species extends to most of the Atlantic waters from Newfoundland and the Labrador basin in the west to the Barents Sea in the east. Monitoring beaked redfish is challenging because of the species wide geographical distribution and large scale migrations; deep distribution, which complicates trawling and hydroacoustic surveys; difficulties with tagging; and persistent difficulties in taxonomic identification. These challenges make it a particularly problematic species to observe with conventional research methods. We review these key challenges and provide recommendations for the coordinated observation of Sebastes mentella in the North Atlantic that would best contribute to the assessment and ecological research on this species.
\end{abstract}

Keywords: Survey design / Trawling / Hydroacoutics / Tagging / Fisheries assessment / Fisheries management

\section{Introduction}

Beaked redfish (Sebastes mentella Travin, 1951) is one of four redfish species of the genus Sebastes found in the North Atlantic. The other three species are golden redfish (S. marinus), Acadian redfish (S. fasciatus) and Norway redfish (S. viviparus). Sebastes spp. are ovoviviparous, i.e. eggs are fertilized, develop and hatch internally and larvae extruded soon after they hatch from eggs. They are long-lived, slow-growing, late-maturing, and have in general low natural mortality. These unique life-history characteristics the influence complex population structure (Cadrin et al. 2010) and make populations highly vulnerable to fishing and slow to recover when depleted.

Beaked redfish is widely distributed in boreal waters of the North Atlantic and adjacent seas of the Arctic Ocean. It is mainly found in the open waters of the Irminger Sea and on the continental slopes and shelves of Greenland, Iceland and the Faroe Islands in the Northwest Atlantic and in the Norwegian

\footnotetext{
a Corresponding author: krik@hafro.is
}

and Barents Seas in the Northeast Atlantic (Andriashev 1954; Templeman 1959; Hureau and Litvinenko 1986; Cadrin et al. 2010). All Sebastes species in the North Atlantic display various kind of pelagic and demersal behaviour during their life span. Sebastes species are ovoviviparous (Hureau and Litvinenko 1986; St Pierre and de la Fontaine 1995) and larvae extrusion takes place in late winter-late spring/early summer, but copulation occurs in autumn-early winter. The larvae ascend to the surface layers $(0-60 \mathrm{~m})$ as they are transported by sea currents from the larvae extrusion areas to the nursery grounds, where the juveniles settle. During the first autumn and winter the 0-group redfish descend to near bottom habitats, although the vast majority of these young and small redfish may live semi-pelagically. When they are 5-6 years old and more, they begin to gradually migrate against the current to locations along the continental slope (Magnússon and Magnússon 1995; Drevetnyak and Nedreaas 2009). In the Northeast Atlantic, mature $S$. mentella extend their feeding out in the Norwegian Sea and return back to a demersal or semipelagic habitat along the Norwegian continental slope where 
they extrude their larvae in March-April. The same is seen in the Irminger Sea where mature $S$. mentella live pelagically.

Beaked redfish has supported an important fishery resource since the early 1950s, but in general the fishery landings have decreased in all areas. The main fishing grounds for beaked redfish in the Northwest Atlantic were traditionally on the continental shelves and slopes of East Greenland, Iceland, and the Faroe Islands. The fishery has mainly been a bottom trawl fishery (ICES 2011b). The pelagic fishery for beaked redfish in the international waters of the Irminger Sea started in 1982 and in the early 1990s two distinct pelagic fisheries developed (Sigurðsson et al. 2006a). In the northeast of the Irminger Sea, within and outside Icelandic EEZ, the fishery expanded to deeper waters $(500-800 \mathrm{~m})$ from spring to early summer, whereas shallower fishery (150-350 m) expanded to the southwest Irminger Sea in the later months of the summer and in the autumn.

Annual landings of pelagic beaked redfish of the period 1982-1993 ranged between $30000 \mathrm{t}$ and $100000 \mathrm{t}$. When the fishery expanded into deeper waters in the northeast Irminger Sea, annual landings rose to a record high of $180000 \mathrm{t}$ in 1996. Since then, catches have declined especially in the shallower waters of the southwest Irminger Sea where very little fishing is now conducted. The main fishery is in the northeast Irminger Sea and annual landings since 2005 have ranged between 30000 and $70000 \mathrm{t}$.

Traditionally, the main fishing grounds in the Northeast Arctic were north of Norway towards Spitsbergen. In the Northeast Atlantic the highest landings were 293000 t in 1976 followed by a rapid decline to $80000 \mathrm{t}$ in 1980-1981 and in 1987 only 10500 t were caught in the Barents Sea. At this time, the fishery expanded further south along the continental slope of Norway at approximately $500 \mathrm{~m}$ depth. After an increase to $49000 \mathrm{t}$ in 1991, the annual landings have remained around $10000 \mathrm{t}$ mainly as bycatch in other trawl fisheries.

A directed pelagic fishery for deep-water redfish in the international waters of the Norwegian Sea has developed since 2004 (ICES 2012a). The annual landings quickly rose to $30000 \mathrm{t}$ but have since then declined rapidly and in 2011, approximately $8400 \mathrm{t}$ were landed from this area.

Surveys have been conducted on pelagic beaked redfish in the Irminger and Norwegian Sea basins since 1983 and 2007 respectively (ICES 2011c, 2009a). These surveys have been conducted by individual nations or in collaboration between two or more nations. The area coverage and methodology have, however, varied and often the area coverage was limited, especially in earlier years. The surveys are mainly hydroacoustic surveys, but since 1999 pelagic trawling has also been used. Over time both the horizontal and vertical coverage have increased as earlier surveys were not considered sufficient for stock assessment purposes (ICES 2011b). In both Northwest Atlantic and the Norwegian and Barents Seas, several other surveys are conducted and relevant for beaked redfish in these areas. Most of them are bottom trawl surveys conducted on the shelves and slopes.

The results from the surveys are the basis for the ICES advice on pelagic redfish in the areas. Until 2012, no analytical assessment was conducted on these stocks and their status was assessed from biomass trends derived from survey indices.

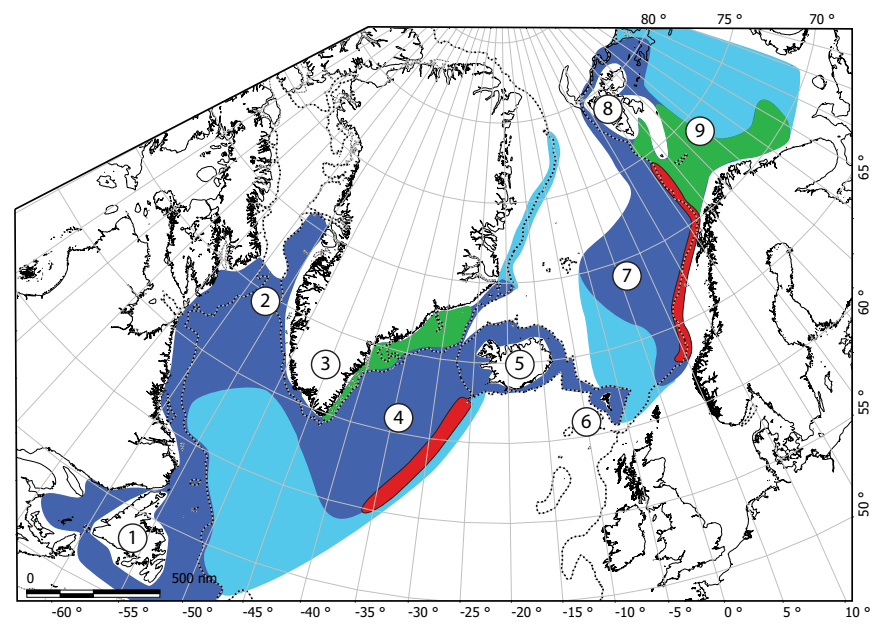

Fig. 1. Geographic range of Sebastes mentella. The dark blue areas indicate the main centres of abundance. The light blue area shows the outer sector of distribution range. The red areas along the slope shows the regions of larvae release. The nursery areas of the Barents Sea and eastern Greenland are indicated in green. The dashed line indicates the $500 \mathrm{~m}$ depth contour. Numbers indicate geographical locations: 1: Newfoundland; 2: Davis Strait; 3: Greenland; 4: Irminger Sea; 5: Iceland; 6: Faroe Islands; 7: Norwegian Sea; 8: Svalbard; 9: Barents Sea. Adapted from Cadrin et al. (2010).

In 2012, ICES conducted a workshop to evaluate and eventually revise the data collection and assessment methodologies used for these stocks (ICES 2012b). In addition to stock assessment, the results from the surveys are necessary to map the vertical and horizontal distribution of beaked redfish, to collect biological data on other fauna, and to monitor the environmental conditions in the areas.

The objective of this contribution is to provide a thorough description of the challenges involved when monitoring beaked redfish (Sebastes mentella) in the North Atlantic with scientific surveys-at-sea and to offer recommendations on how such monitoring could be conducted in the future. For this purpose, we review the key challenges regarding research on beaked redfish and we explore possibilities for the coordinated observation of beaked redfish in the North Atlantic that would best contribute to the ecological research and assessment of this species. Data from commercial fisheries, which are also used to support assessment, offers particular challenges which are not considered is this review.

\section{Geographical extent}

Sebastes mentella is widely distributed in boreal waters of the North Atlantic and adjacent seas of the Arctic Ocean. Its habitat in the West covers the area from Nova Scotia to Baffin Island and Disko Island near West Greenland; in the East, it covers the area from the Northern North Sea along the continental coast and extends northward and northeastward to the Norwegian and Barents Seas. The species occurs on the Faroe-Iceland Ridge, in the waters of Iceland and East Greenland (Fig. 1, Andriashev 1954; Templeman 1959; Hureau and Litvinenko 1986; Cadrin et al. 2010). The area 
of pelagic distribution of the species is around 660000 nautical mile ${ }^{2}$ for the Irminger and Norwegian Seas combined. To cover this area with transect-based hydroacoustics surveys, following the protocols presently in use in the Irminger and Norwegian Seas would require 130-150 days-at-sea. Additional effort is needed to survey the demersal components on continental shelves. This situation imposes international collaboration (ICES 2009a).

\section{Pelagic-demersal mixing}

Because $S$. mentella is found demersally and pelagically and since the depth distribution of redfish extends down to $\sim 1000 \mathrm{~m}$, the species is usually not well sampled by conventional demersal or pelagic fish assessment surveys, and rather requires dedicated sampling protocols. Most of the research survey abundance time series from the continental shelf are abundance indices estimated from bottom trawling sampling the a layer of few meters above the sea floor. Using hydroacoustic registrations, it is possible to calculate the ratio between acoustic redfish $s_{A}$ values in the pelagic water column above 10 meters from bottom and the acoustic redfish $s_{A}$ values within the $10 \mathrm{~m}$ bottom layer. This ratio constitutes a proxy for the proportion of redfish population actually sampled by bottom trawling surveys. This approach was used by the North East Atlantic Fisheries Commission (NEAFC) working group collating information on the distribution of Sebastes mentella in ICES sub-areas I and II (Anonymous 2009). The acoustic benthic/pelagic ratio was estimated based on nine surveys (more than $12000 \mathrm{NM}$ ) in the Barents Sea and Svalbard (Spitsbergen Archipelago). In this region, the ratio estimates varied from $72 \%$ to $85 \%$ during all those surveys, with an average of $80 \%$. A similar exercise, conducted on the Norwegian continental slope showed that about $90 \%$ of beaked redfish are located above the $10 \mathrm{~m}$ bottom layer.

Little is known about the mechanisms that trigger a pelagic or demersal behaviour, but it is related to size (age), search for food and mating/larvae extrusion. Among the Sebastes species, $S$. mentella is probably the species that change between demersal and pelagic habitats most frequently and to the greatest extent.

\section{Longevity}

The age determination of S. mentella is generally difficult, time-consuming and highly variable (e.g., ICES 2009c). For some stocks, indirect validation by following peaks in the length distributions has been attempted (e.g., Saborido-Rey et al. 2004). Only few studies, however, have been conducted for direct validation (radiometric otolith analyses by Campana et al. 1990; Stransky et al. 2005), but these remain baseline studies due to their high methodological effort. For $S$. mentella in the Irminger Sea, longevity of at least 40 years has been confirmed (Fig. 2).

A promising validation technique that can (and should) be combined with tagging (Sect. 13) is oxytetracycline (OTC) marking of juveniles in order to follow growth increments in the otoliths from the time of marker injection (e.g. Greenland halibut: Treble et al. 2008).

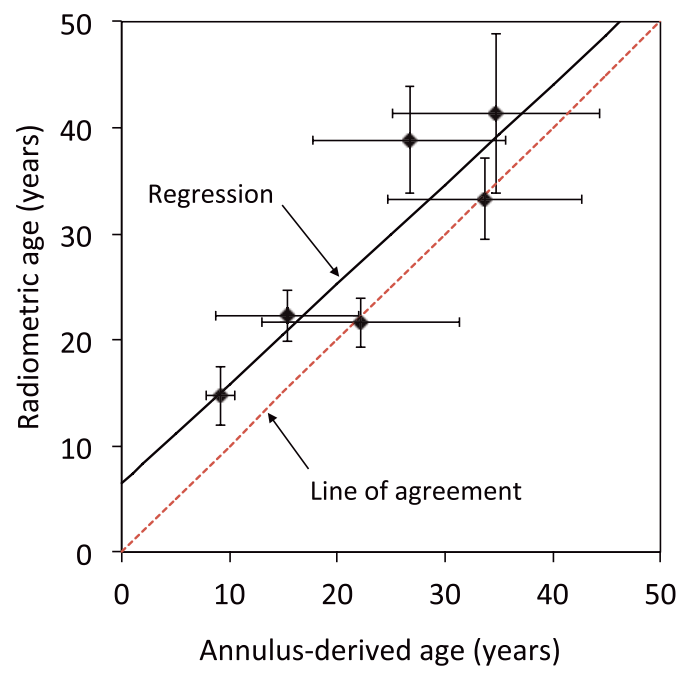

Fig. 2. Age estimates from otolith annulus counts for S. mentella in the Irminger Sea in relation to radiometric ages calculated from leadradium activity ratios. Error bars represent \pm 1 SD. Redrawn after Stransky et al. (2005).

\section{Recruitment}

As for many fish populations, the processes driving the year-to-year fluctuations in the recruitment of redfish are still poorly known. Based mainly on ichthyoplankton surveys and the observation of gravid females, two main areas of larval extrusion have been identified (Magnússon and Magnússon 1995; Rikhter 1996; Melnikov et al. 2001): close to the Reykjanes Ridge in the Irminger Sea and along the continental shelf break off Norway (from $62^{\circ} \mathrm{N}$ to $74^{\circ} \mathrm{N}$, Fig. 1). The released larvae drift to their nursery grounds on the shelf of eastern and western Greenland and into the Barents Sea and the adjacent continental slope, respectively (Sect. 8).

Genetic analyses of redfish samples from the East Greenland shelf are currently undertaken to investigate the stock structure of $S$. mentella in this important nursery area. If technically feasible, tagging juvenile redfish (see Sect. 13) on their nursery grounds would give valuable insight into the migration pattern of the juveniles, when recruiting to the adult stock(s). Another possible method for investigating the pattern and quantity of this recruitment is by following peaks in prominent length classes over the years, observed on the shelf in standard surveys like the annual German groundfish survey off West and East Greenland (Stransky 2000). A detection of these length classes (as a proxy for age classes) in certain areas or depths of adjacent waters would identify the recruitment patterns and eventually help quantifying the recruitment. There are several open questions regarding the recruitment (e.g. causes for variability, environmental factors, and natural mortality). The causes of the often observed variability are mainly unknown and the quantification of a potential recruitment based on scientific surveys in the nursery areas like the Greenland shelf are impaired by difficulties in reliably discriminating the different Sebastes species for small size individuals (17 cm and below, Sect. 7). Species identification is a pre-requisite for understanding the population dynamics of S. mentella since different Sebastes species can share the same nursery grounds. 


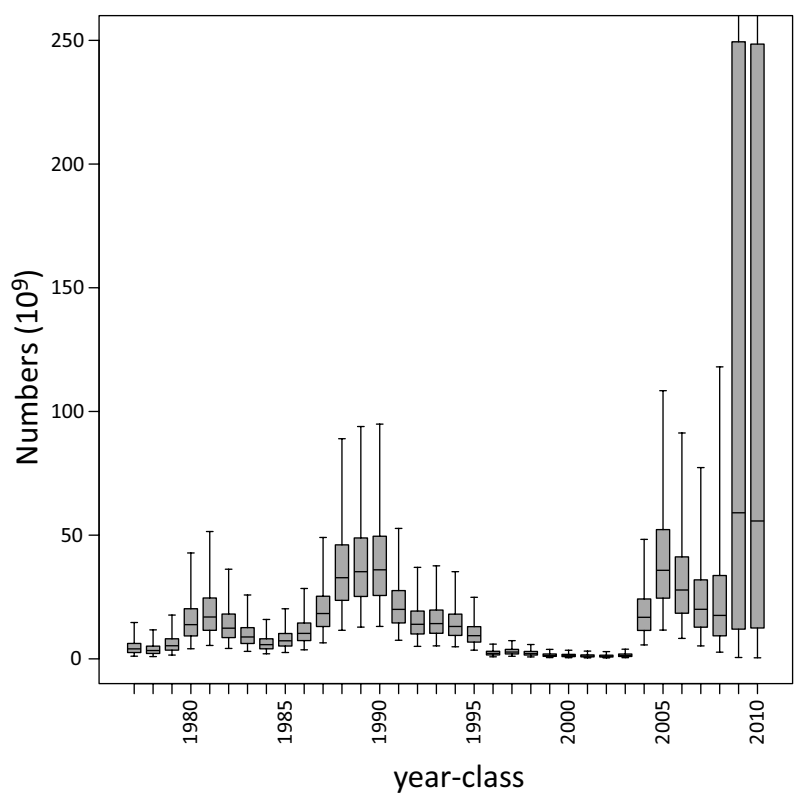

Fig. 3. Modelled index of year-class strength of $S$. mentella in the Norwegian/Barents Sea for the period 1977-2010. The median estimate is indicated by the horizontal line in each box. Box edges outline the 25 and $75 \%$ distribution percentiles and whiskers show the $2.5 \%$ and $97.5 \%$ percentiles. In 2009 and 2010, the upper part of the distribution is off scale. Redrawn after Planque et al. (2011).

In the Norwegian and Barents Seas, the situation is somehow similar but $S$. mentella juveniles generally occur over a wider area and in larger numbers than the other two species (S. marinus and S. viviparus), so that the total number of $\mathrm{Se}$ bastes spp. juveniles is a good proxy for the abundance of juveniles of $S$. mentella. In recent years, an analytical model for year-class strength (Planque et al. 2012) and a statistical catchat-age model (ICES 2012b) were developed for S. mentella in the Norwegian Sea. These have permitted reconstruction of the recruitment history back to 1992. During the period 19962003 , recruitment in this area was extremely reduced whilst the mature stock biomass was not particularly low, which indicates that there is no obvious connection between the size of the mature stock in a given year and the level of recruitment for the associated year-class. However, year-class strength has been increasing since 2004 and is currently estimated at the highest level since the beginning of the time series (Fig. 3). Recruitment time-series derived from analytical models are not available for the Irminger Sea stock(s).

\section{Meta-population}

The meta-population structure of beaked redfish is a vivid area of research. The main conclusions of the workshop on Redfish Stock Structure (WKREDS, ICES 2009d) of the International Council for the Exploration of the Sea (ICES) which were not unanimously approved by the participants indicate that, based primarily on genetic information, four different stocks can be identified in the Irminger Sea and adjacent waters. These are separated horizontally and vertically but partly share an important nursery area, the East Greenland shelf. In contrast, the exact stock structure in the Norwegian and Barents Seas remains unresolved. Results of genetics, fatty acid analyses, morphometrics and otolith morphology (summarised in Cadrin et al. 2010) suggest that the Norwegian and Barents Sea stock, and S. mentella dwelling east of the Faeroes, may form one distinct stock. The connectivity between the two large areas of the North Atlantic, the Irminger Sea and adjacent waters in the west, and the Barents and Norwegian Seas in the east, but also between smaller areas like the shelf east and west of the Faeroes remain unknown. The exact meta-population structure remains heavily debated in the scientific community and divergent views exist on the validity of proposed stock divisions, in particular in the Irminger Sea. In contrast to Cadrin et al. (2010), Makhrov et al. (2011) suggests that there is only one population of beaked redfish in the Irminger Sea area.

There are mainly three questions that arise concerning $S$. mentella in the North Atlantic: (1) does S. mentella function as a metapopulation in the North Atlantic? (2) Do local populations act as sink or source of juvenile migrants in the metapopulation? And (3) to what extent can the commercial fishery affect the persistence at local and metapopulation levels? A more complete description of migration of adult fish between the habitats of the different stocks or the recruitment of juvenile fish from nursery areas into the adult stock would help in answering these questions (see Sects. 5 and 8). This might be achieved by tagging studies, using dedicated underwater tagging equipment (Sect. 13 and Sigurðsson et al. 2006b). Additionally, further extensive genetic studies over the whole geographical distribution area are essential for classifying the different populations into management units.

\section{Species identification}

The four Sebastes species in the North Atlantic have very similar external morphological features, which make their differentiation difficult. As a result, catches are often reported for "redfish" without species specification. This is the case in the Northwest Atlantic where S. mentella and S. fasciatus are managed together as beaked redfish, and in the Northeast Atlantic where many fisheries regulations are not species specific because $S$. marinus and $S$. mentella are not reported separately. Morphometric studies have been used to distinguish Sebastes species and populations on both sides of the Atlantic (Misra and Ni 1983; Power and Ni 1985; Kenchington 1986; Saborido-Rey 1994). An illustration of morphological characteristics for young specimen is given in Figure 4. The EU Redfish project (2000-2003, Anonymous 2004) involved collaborative sampling efforts and analyses of genetics, morphometrics, reproduction and maturation, otolith shape, otolith chemistry, and growth. The overall conclusion of the results of the morphometric analyses is that the four Sebastes species inhabiting the North Atlantic are morphometrically distinct, but with gradients and differences within species between areas. The external features normally used to identify species have been revealed as problematic for a real identification of the species around the Faroes and off Greenland.

In the 1990s, investigations using electrophoresis revealed diagnostic criteria to separate the Sebastes species 


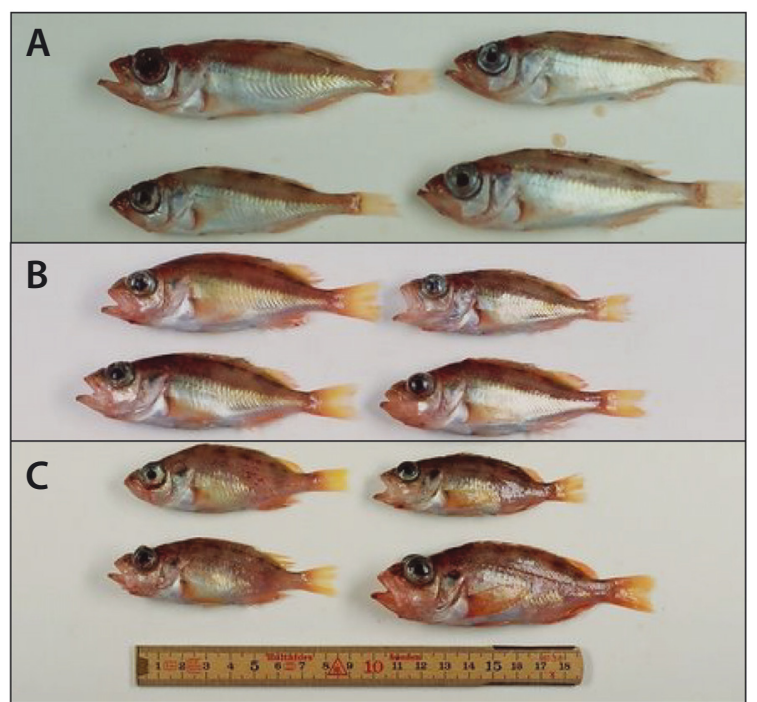

Fig. 4. Photographs of young specimens of the three Sebastes species commonly found in ICES areas I and II. Key identification features are indicated. A) Sebastes mentella, pronounced tap on the lower jaw/lip, silverfish pigmentation of the entire belly side from head to tail. B) S. marinus, No pronounced tap, the pigmentation of the belly side is more golden, more stunt body shape than $S$. mentella. C) $S$. viviparus, the body shape is round and stunt especially on the back of the fish, no silversish pigmentation of the belly behind the anal opening, the preopercular spines are all pointing straight backwards.

(e.g., Nedreaas and Nævdal 1989, 1991a,b; Nedreaas et al. 1994). Haemoglobin was shown to be a good diagnostic for $S$. mentella but $S$. marinus and $S$. viviparus show the same haemoglobin pattern. Sebastes specimen less than about $60 \mathrm{~mm}$ had not achieved the adult haemoglobin pattern hence making impossible to differentiate the young fish. The genetic structure of the enzyme malate dehydrogenase (MDH) is diagnostic for $S$. viviparus, and joint analyses of haemoglobin and $\mathrm{MDH}$ can achieve separation between $S$. marinus and the other two species.

Patterns of genetic variations in DNA among and within species of the genus Sebastes are summarized in Cadrin et al. (2010). Since the main focus in these works has been related to variation within species and population genetics, a protocol describing procedures and methods to use for diagnostic identification of species using DNA techniques is still lacking. It can though be mentioned that Johansen and Dahle (2004) investigated this by polymerase chain reaction (PCR)-based random amplification of polymorphic DNA (RAPD). They found that only one primer, OPA20, could be used to diagnostically distinguish among species.

\section{Seasonal migrations}

Spatial and seasonal migration patterns of S. mentella in the Irminger Sea and adjacent waters and in the Norwegian and Barents Seas are still largely unidentified although it is known that adult $S$. mentella undertake large migrations between copulation grounds, larval extrusion grounds and feeding grounds (Magnússon and Magnússon 1995; Anonymous 2009). Beaked redfish in both areas have similar life cycle, i.e. males and females mature at different times, copulation occurs in autumn and larval extrusion in spring.

In the Irminger Sea, males mature in August-November, at the time of copulation, but the copulation areas are unknown (Anonymous 2004). After larval development, females migrate to the open ocean where larval extrusion occurs from April to June with peaks in late April/early May (Magnússon and Magnússon 1995). Pelagic fry drift to nursery areas that are found along the coast of East and West Greenland, where they settle to the bottom (Magnússon and Magnússon 1995). As juveniles mature they migrate into the stocks found in deeper shelf areas and in the pelagic zone into the Irminger Sea and adjacent waters. After extrusion of larvae, adult redfish migrate northward towards the slopes of north-western Iceland and East Greenland, and to the west and southwest towards the shelf and slopes of East Greenland (Sigurðsson et al. 2006a; Cadrin et al. 2010). Very little is known about the adult distribution from September to March, before the larvae extrusion starts again.

In the Norwegian and Barents Seas, larval extrusion occurs along the continental shelf break from $64^{\circ} \mathrm{N}$ to $74^{\circ} \mathrm{N}$ in March-April. Larvae drift northward along the continental slope in the surface layer towards the Barents Sea and shelf waters around Spitsbergen. Juveniles are mainly distributed in the Barents Sea and along the continental slope (Drevetnyak and Nedreaas 2009). After extrusion, adults migrate to the open Norwegian Sea where a large fraction resides during summer and autumn at depths ranging from $150 \mathrm{~m}$ to $800 \mathrm{~m}$.

Very little is known about the migration between the Norwegian and Irminger Seas, although genetic studies suggest that the individuals found in the shallow Irminger Sea and in the open Norwegian Sea could belong to the same population. To date only limited genetic studies have been carried out on S. mentella in the Norwegian and Barents Sea and these suggest that only a single population inhabits these areas (Cadrin et al. 2010).

Our current knowledge of the seasonal migration patterns of beaked redfish remains elusive and is derived from seasonal observations of the population through scientific surveys and by following the spatial distribution of the fishery (Drevetnyak et al. 2011).

\section{Link to hydrological features, spatial range and climate change}

The geographical and vertical distributions of Sebastes mentella in the North Atlantic are subjected to interannual variations that can affect the fishery. For example, in the first years of the pelagic fishery for $S$. mentella in the Irminger sea, the shallow $(<500 \mathrm{~m})$ and the deep $(>500 \mathrm{~m})$ stocks had a similar horizontal distribution, but the two stocks and fisheries have been widely separated since the late 1990s. The spatial distribution of $S$. mentella in the Irminger Sea seem to be related to water temperature distribution, with a preferred thermal range of $4-6{ }^{\circ} \mathrm{C}$, as illustrated in Figure 5 (ICES 2009b).

The physical oceanography in this region is variable (Hátún et al. 2009) and is dominated by the dynamics of the North Atlantic Sub-Polar Gyre (SPG), a large counter-clock 

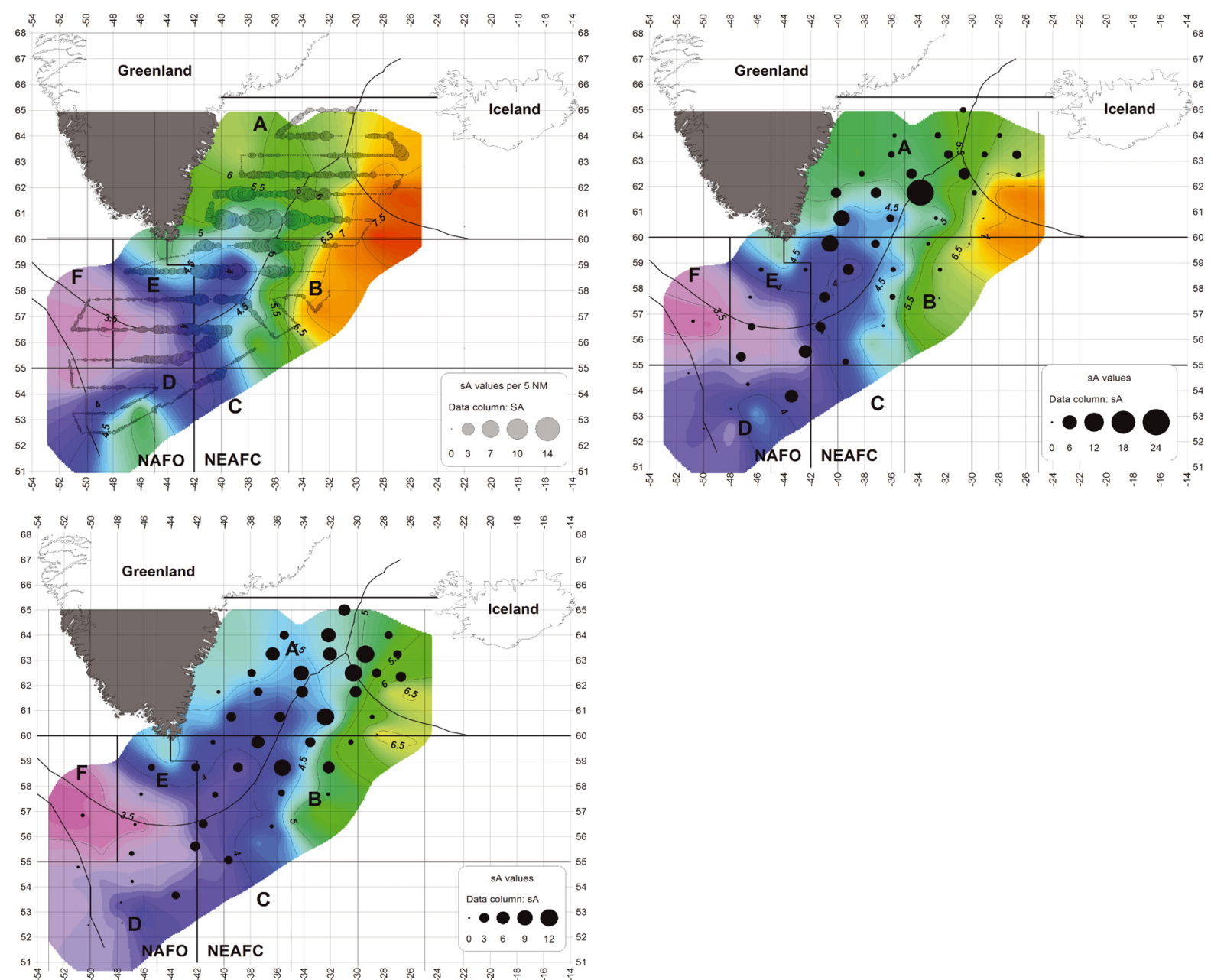

Fig. 5. Temperature distribution (colour) and redfish distribution (bubbles) as recorded during the international redfish survey in the Irminger Sea and adjacent waters in June/July 2009. Top-left: temperature at $200 \mathrm{~m}$ depth and redfish distribution derived from hydroacoustics. Topright: temperature at $400 \mathrm{~m}$ depth and trawl-catches shallower than $500 \mathrm{~m}$. Bottom-left: temperature at $600 \mathrm{~m}$ depth and trawl-catches deeper than $500 \mathrm{~m}$.

rotating body of relatively cold and low-saline subarctic water in the central northern North Atlantic. The distribution of S. mentella is confined within the SPG (Pedchenko 2005). During the early 1990 s the circulation of the gyre was intense, but declined substantially after 1995 leading to a rapid warming and increased salinity (Hátún et al. 2009). As suggested by Pedchenko (2005), it is possible that the SPG influences the upper and lower water masses in the Irminger Sea differently, thereby explaining the different horizontal distribution of $S$. mentella in the shallow and the deep Irminger Sea.

Recently, the ICES Workshop on Redfish and Oceanographic Conditions (WKREDOCE, ICES 2012c) compiled and analysed time series from trawl surveys, acoustic surveys, commercial fisheries and oceanographic measurements to explore the relationships between beaked redfish distribution and hydrographic conditions. The main conclusions of WKREDOCE were the following: A relationship was established between seasonal and interannual movements of pelagic beaked redfish in the Irminger Sea and ocean currents and their associated physical properties (temperature and salinity). A decrease in the North Atlantic Oscillation (NAO) index strength since 2008 and the present deceleration of the Sub-Polar Gyre (SPG) suggest a subsequent northeast displacement of redfish in the coming years. No relationship was established between the overall abundance of redfish and oceanographic conditions.

However, there are important limitations in the data and analyses used to draw these conclusions. In particular, no distinction was made between the two S. mentella stocks in the area, very few depth data were presented and the movements of the fishing fleet was assumed to reflect movements of the fish. The conclusion on interannual movements is valid for the shallow $S$. mentella stock, since most of the oceanographic changes are in the upper 4-500 m. The evidence for seasonal movements remains elusive since it is mostly based on the movement of the fishing fleet rather than on direct observations of the stock distribution.

In the Norwegian and Barents Sea, the distribution of S. mentella seems confined within Atlantic waters in a similar way to the confinement of the species in the SPG in 


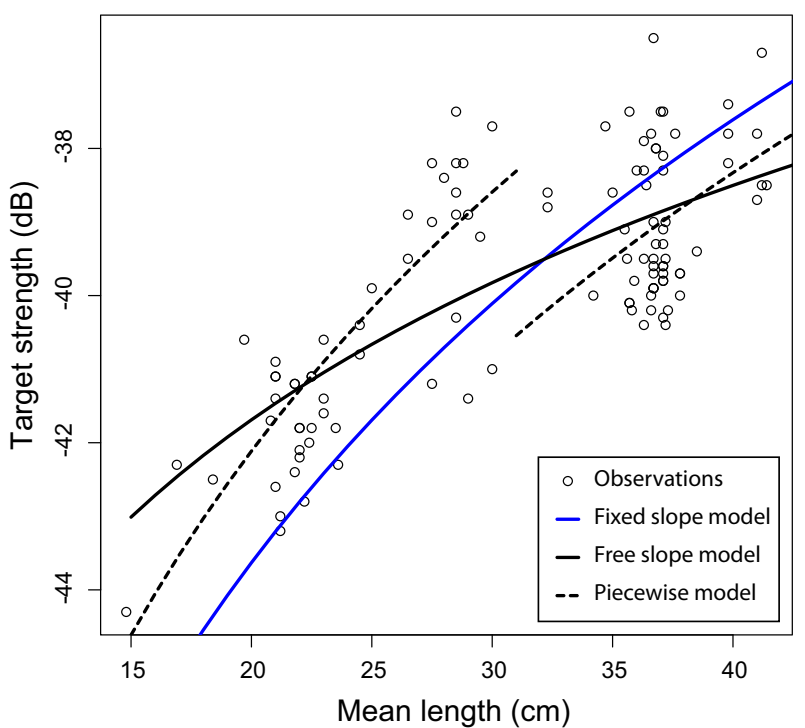

Fig. 6. Fit of TS-length equations based on a meta-analysis of past records of Sebastes target strength. Blue dots: individual data points. Red and blue lines show fit of the fixed-slope model $(20 \log (L)$, with 2 different weighting schemes) and black line show the fit of the free slope model. The green line shows the fit of a piecewise model with fixed slope and different intercepts for small $(<31 \mathrm{~cm})$ and large (>=31 cm) fish. Reproduced from ICES (2010).

the Irminger Sea. Investigations conducted in the Norwegian Sea in 2008 indicate temperature preference between -0.5 and $5.0^{\circ} \mathrm{C}$ (ICES 2008), a wider thermal range than observed in the Irminger Sea.

\section{Target strength}

Measuring the target strength (TS) of $S$. mentella remains a difficult task. In contrast to other species, it is nearly impossible to catch beaked redfish alive due to barotraumatism, and this excludes direct measurements on caged fish (e.g., Gauthier and Rose 2001). The use of a $T S$ probe (Ona and Svellingen 2001) can also be problematic because the density of individual $S$. mentella (number $\mathrm{m}^{-3}$ ) is generally so low that it is difficult to get individuals into the $T S$ probe detection volume. A more practicable solution has been attempted with in situ measurements, by comparing the distribution of the crosssection of targets, computed from the length distribution of the catch, with the cross-section distribution obtained from the measured TS distribution (e.g., Ermolchev 2009). The state of the art data are currently the results obtained by Reynisson and Sigurdsson (1996) and Pedersen et al. (2005). These Icelandic data, were reanalysed with a focus on the problem of multiple echoes by Reynisson and presented at the workshop WKTAR in 2010 in Troms $\varnothing$ (ICES 2010). A TS-value of $-39 \mathrm{~dB}$ was estimated for S. mentella observed during daytime at a depth below $300 \mathrm{~m}$ with a mean length of $36.9 \mathrm{~cm}$. For the standard length based $T S$-equation $T S=20 \log (L)-K$ (where $L$ is fish body length and $K$ is the intercept parameter of the regression), a value of $K=70.3$ was estimated. Norway carried out $T S$ measurements during the EU-redfish project in June-July
2001 also in the Irminger Sea applying a hull mounted transducer and a transducer mounted in a towed body; both connected to a Simrad EK60 echosounder. Estimated intercept $K$ had a mean value of 70.2. The most recent synthesis of target strength measurements across the whole North Atlantic is provided in the report of the workshop on the Determination of Acoustic Target Strength of Redfish (WKTAR, ICES 2010). This was achieved through an extensive review of published and ongoing studies, from which data were evaluated, ranked, and served as input to a meta-analysis. The results indicated that the best candidate for a general model of S. mentella $T S$ length equation at $38 \mathrm{kHz}$ is the free slope model: $T S=10.6$ $\log (L)-55.4$ (Fig. 6). The fixed slope model resulting from this analysis has a $K$ value of 69.7. However, the meta-analysis revealed important departures from this equation in individual studies and the reasons for such discrepancies are generally undetermined or at best poorly documented.

\section{Scrutinizing of echograms}

In the open ocean, the distribution of S. mentella is scattered and a large proportion of the redfish biomass is positioned within the deep scattering layer (DSL, see Sect. 16). In this layer, redfish are mixed with various abundant smaller animals (myctophid fishes, cephalopods, shrimps, jellyfishes, etc., see Table 6 in ICES 2009a) that generate acoustic reverberation. Such reverberation can hardly be separated from the individual target signal. In the Irminger Sea, hydro-acoustics registrations are used to derive biomass estimation above the DSL, whereas abundance estimate within and below the DSL are derived using a conversion of the catches into equivalent acoustic values named $s_{A . t r}$. In contrast, in the Norwegian Sea, hydroacoustics registrations are used to derive biomass estimates above, within and below the DSL, with varying degrees of success. The methodology applied in the Irminger Sea is justified by (1) the difficulty to acquire hydroacoustics registration below the DSL with sufficient quality when using a hull mounted transducer (Sect. 12) and (2) the high acoustic reverberation in the DSL produced by many organisms of unknown target strength (Sect. 16). The methodology currently in use (Mamylov 1999) is illustrated in Figure 7. Above the DSL, S. mentella is found in the depth range $200-350 \mathrm{~m}$ where hydroacoustics is little disturbed by vessel noise. A regression model between trawl catches and $s_{A}$ values is constructed, using combined catch and hydroacoustic data from pure redfish aggregation.

For the Norwegian Sea, the scrutinizing methodology was reviewed during a dedicated workshop (Planque et al. 2009). Comparative analyses conducted during this workshop showed that differences in scrutinizing methods had a very large impact on the abundance estimate of redfish and may constitute the major source of uncertainty for quantitative abundance estimates. Some of the specific recommendations that were made at the workshop - to reduce these uncertainties - are reproduced below:

- Hydroacoustics should be used in addition to trawl based estimates. For that purpose, the number of trawl samples should be maximized. 


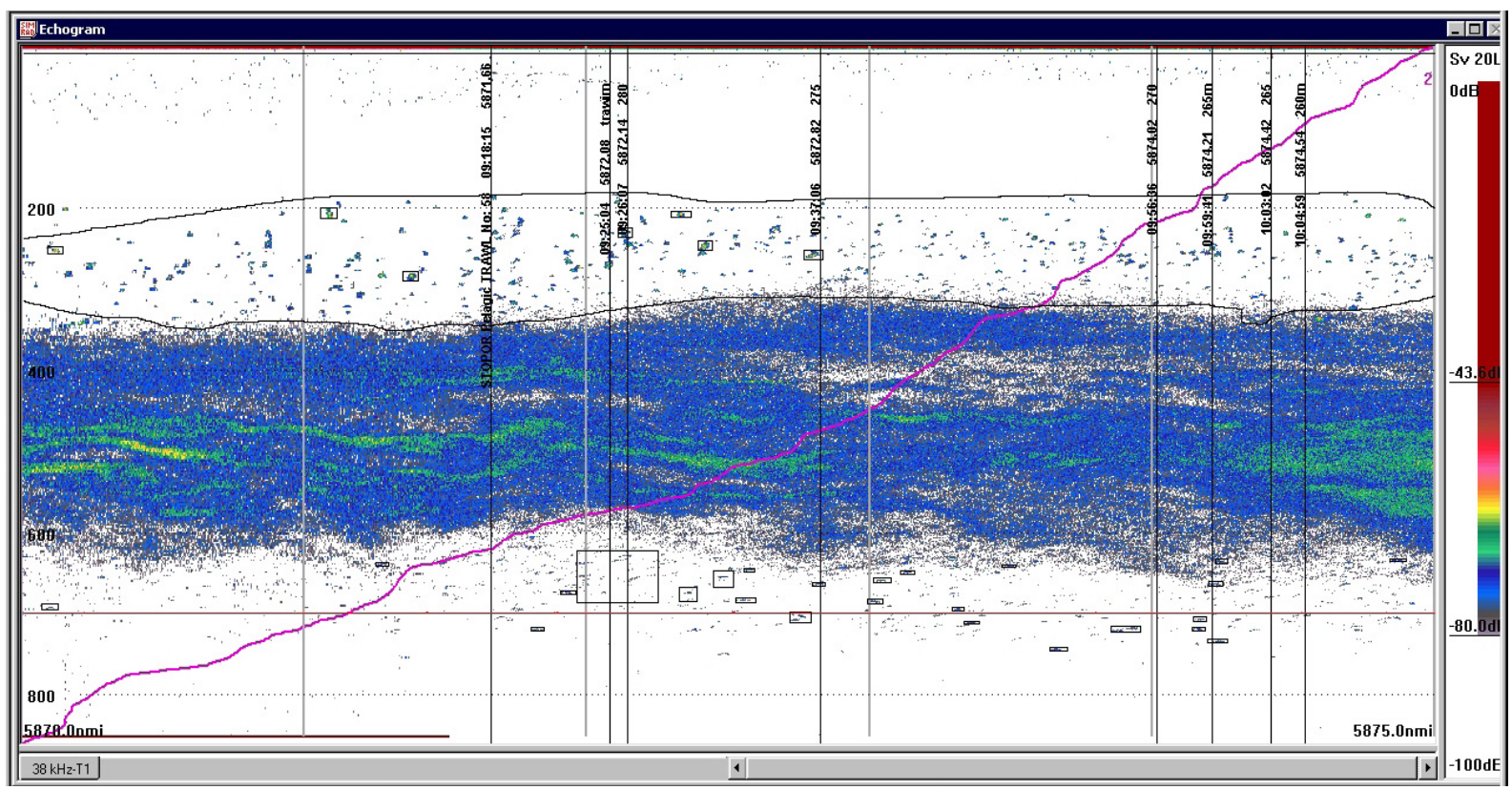

Fig. 7. Echogram recorded by Russian RV "Smolensk" over 5 nautical miles during the summer 2007 survey in the Irminger Sea (38 kHz, pulse length $2 \mathrm{~ms}$ ). The dense layer is the deep scattering layer (DSL) in which redfish are mixed with other small organisms. Pure redfish aggregations distinctly visible above DSL in the acoustic layer (contoured by layer tool of scrutinizing software). Single targets of redfish below DSL are also visible (contoured by rectangles). Reproduced from ICES (2007).

- All vessels should use the same equipment for trawling (Gloria midwater trawl 2048), hydroacoustic registering (Simrad EK60 echosounder) and scrutinizing.

- Individual trawl hauls should be conducted horizontally, in single vertical layers (e.g. above, within or below DSL).

- 1-2 days should be allocated to inter-vessel calibration of acoustic systems and trawls.

- Workshops for scrutinizing cross-comparison should be conducted systematically, as a measure of data qualification.

\section{Deep distribution 1: hull mounted vs. deep towed hydroacoustics}

On the continental shelves and slopes many individual fish are located in the neighbourhood of the sea floor but there is also a large pelagic fraction (80-90\%). In the open basins of the Norwegian Sea and Irminger Sea the pelagic distribution is typically between $300 \mathrm{~m}$ and $600 \mathrm{~m}$ and is located in or below the acoustic deep scattering layer (DSL).

Acoustic energy echoed by a single target is inversely proportional to the 4th power of the range between the hydroacoustic source and the target, whilst acoustic noise (such as that generated by the vessel) is independent from the range. The fact that most adult redfishes are distributed at depths that exceed $300 \mathrm{~m}$ and often below $500 \mathrm{~m}$ therefore makes it difficult to use hull mounted transducers, which in such conditions unavoidably operate with poor signal-to-noise ratio. In addition, as the area of the acoustic beam increase with the power of the range, the chance of hitting simultaneously multiple targets increases with depth, therefore reducing the resolution of the detections and the ability to perform scrutinizing, echo counting or estimates of target strength. To reduce these problems Dalen et al. (2003) have used a deep towed transducer rather than the conventional hull mounted one. The idea was to move the transducer closer to the fish targets, thereby increasing the signal to noise ratio and sampling resolution (Fig. 8, Dalen et al. 2003). Abundance estimates using the deep towed transducer were superior to those from the hull mounted one. Below the DSL the abundance estimates could be up to $55 \%$ higher, when using the deep-towed transducer.

\section{Deep distribution 2: tagging}

Tagging has been used in fisheries research since the late 19th century (Petersen 1896) and is a primary tool for studying the behaviour of fish, even more so since the advent of electronic tags (Arnold and Dewar 2000).

Most redfish species in the North Atlantic have been considered impossible to tag by conventional methods because fish are unable to release the air of their swimbladder fast enough when they are brought up to the surface. As a result, the swimbladder may expand and rupture and the expanded air can push the internal organs out through the oesophagus and mouth. Attempts have been made to overcome this obstacle with various techniques and varying degrees of success (Hislop 1969; Jones 1979; Priede and Smith 1986; Armstrong et al. 1992; Schauer et al. 1997). The Marine Research Institute in Reykjavík, Iceland, in collaboration with Star-Oddi Ltd. have approached the problem of tagging redfish by designing and building an Underwater Tagging Equipment (UTE) which makes it possible to tag redfish by a robot (Fig. 9), in the fish's 


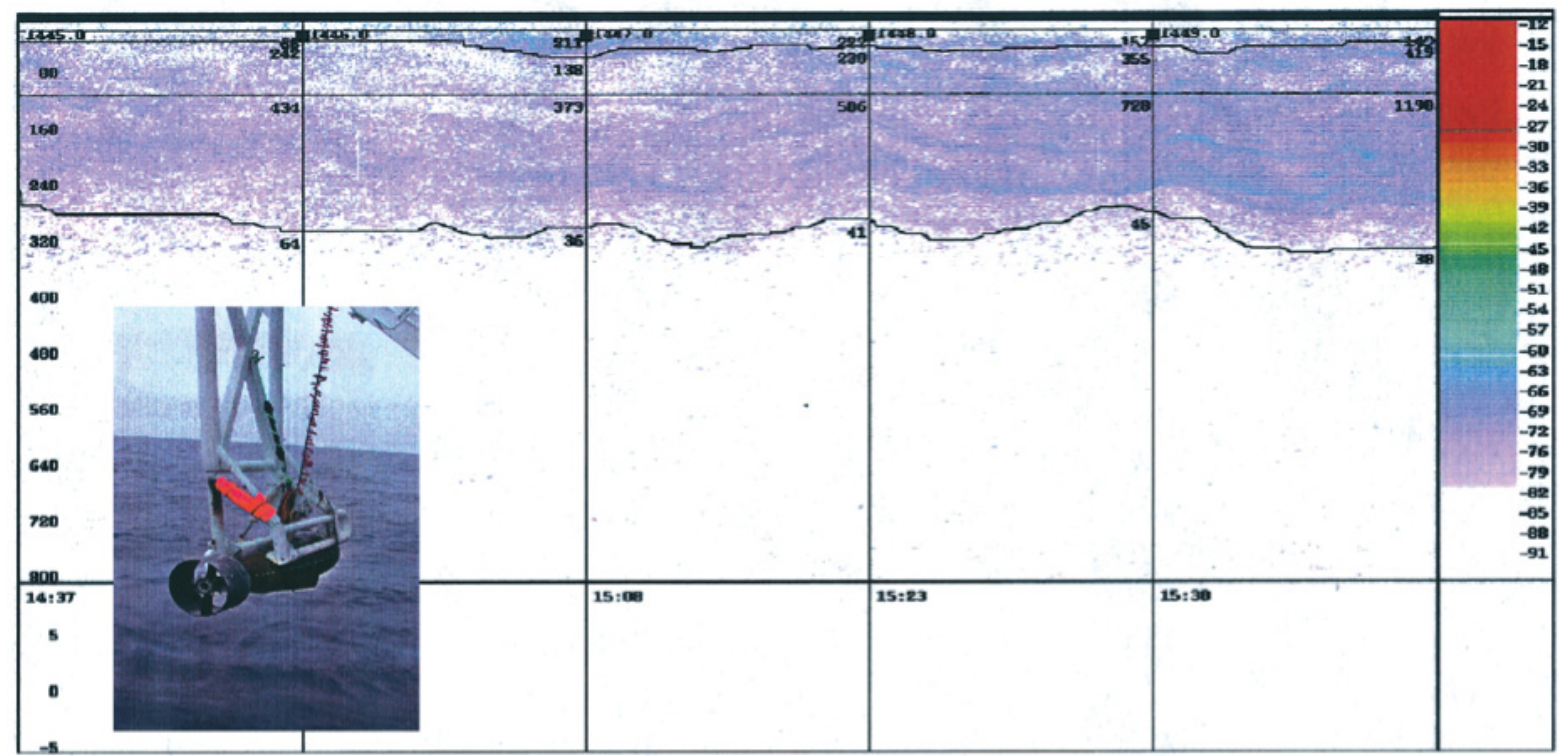

Fig. 8. An echogram from the EK500 at $38 \mathrm{kHz}$ with hull-mounted transducer. Numbers at the top indicate ship log (nautical mile). Numbers on the left indicate depths $(\mathrm{m})$. Depth extension is $350-1100 \mathrm{~m}$. Zero metre represents $350 \mathrm{~m}$, which equals the depth of the vehicle. The colour bar displays the scale of the volume-backscattering strength. The insert shows the deep-towed vehicle being launched into the Irminger Sea. Reproduced from Dalen et al. (2003).

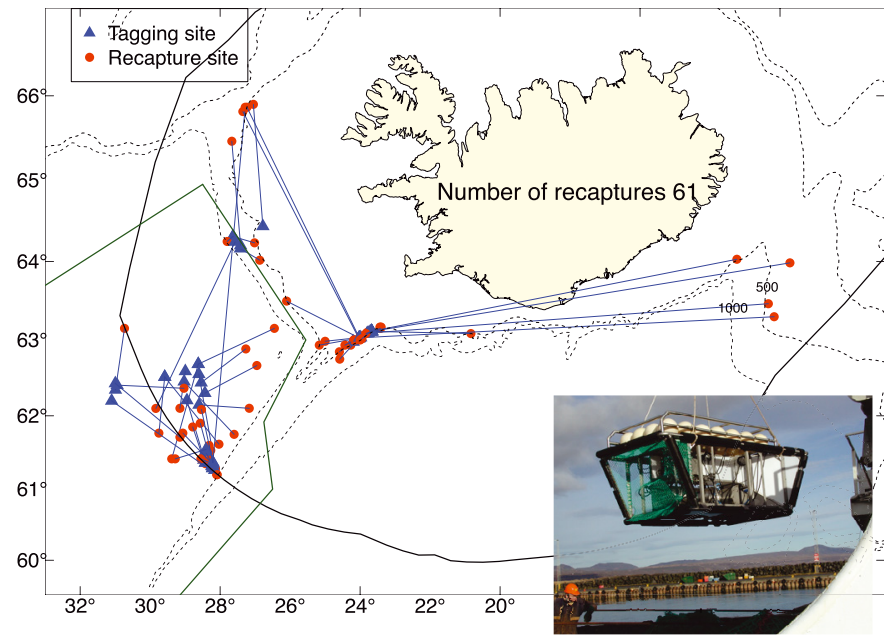

Fig. 9. Tagging and recapture locations for deep-sea redfish tagged since October 2003. Red circles indicates recaptures and blue triangles indicates the tagging site. The lines between the two points indicate the shortest distance between the two positions. Updated from Sigurðsson et al. (2006). Inlet: the Underwater Tagging Equipment (UTE). Photo: Th. Sigurðsson.

own environment, thus avoiding the hazardous trip to the surface (Sigurðsson et al. 2006b). This allows for collection of precise information on vertical and horizontal migration patterns of the various stocks of redfish, as well as biological information, such as growth.

Since 2003, five cruises have been conducted to tag redfish, in the Irminger Sea and on the shelves southwest and west of Iceland. During these cruises more than 2400 redfish were tagged. In total, 61 recaptures have been reported to MRI (Fig. 9) with fish having been in the sea for up to 6 years from tagging. Although the underwater tagging equipment has proven to be successful for tagging redfish at great depths, only Iceland has used it to date. Increased international effort in tagging experiments could significantly contribute to improving knowledge on S. mentella life history, biology and ecology.

\section{Deep distribution 3: stomach content}

Information on trophic relationships of S. mentella in the Irminger and Norwegian Seas is scarce. Observations show that deep-sea redfish in the Irminger Sea are opportunistic feeders that graze within the deep scattering layers mostly at 300-800 m depth and feed on invertebrates and small fish (Magnússon 1996). The most important food items are Copepoda, Euphausiacea, Mollusca, Decapoda and Myctophidae (Magnússon 1996; González et al. 2000; Pétursdóttir et al. 2008; ICES 2009a). Stomach content analyses are however rather difficult because a high proportion of redfish have everted stomachs when hauled to the surface. In such situation, it is problematic to evaluate feeding condition and food composition and hence it is difficult to investigate trophic interactions in the area. Research on feeding and trophic interactions requires the collection of representative stomach samples. The UTE (see Sect. 13) could be used for this purpose, if modified to sample whole fishes inside a plastic bag that can retain stomach content. The use of fatty acid and stable isotope analyses (Pétursdóttir et al. 2008) constitute complementary approaches. 


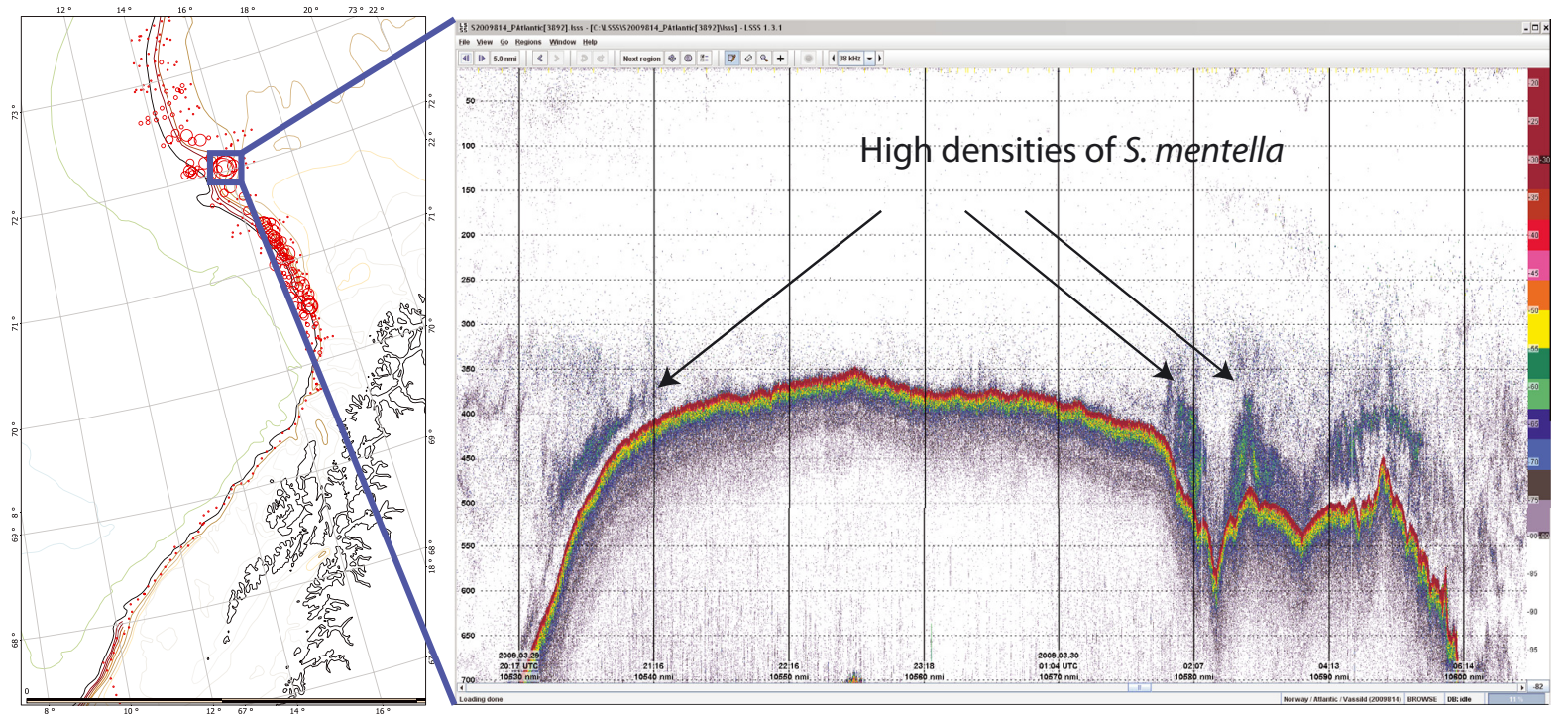

Fig. 10. Left: the spatial distribution of redfish along the continental slope off Norway in spring 2009, as recorded with hydroacoustics. The neighbouring large circles (high abundance) and small circles (low abundance) indicate patchy distributions at small spatial scales, in addition to large scale gradients (e.g. higher abundance to the North of $70 \mathrm{~N}$ than to the south). Right: hydroacoustics registrations over the shelf and slope at $72 \mathrm{~N}$ showing dense aggregations of redfish over regions of few nautical miles. Total transect distance is 70 nautical miles.

\section{Patchy distributions on shelves}

Over the oceanic regions, the pelagic distribution of redfish is rather smooth as can be observed from the acoustically derived spatial distribution maps $S$. mentella in the Irminger Sea (ICES 2009b) and northern Norwegian Sea (ICES 2009a). In such conditions, regular acoustic survey designs with sufficiently small distances between transects, are usually suitable to derive accurate abundance and biomass estimates for the entire area surveyed. The situation over the continental shelves and slopes can be rather different with high variation in the density of fish over small distances. This has clearly been observed over the Norwegian Sea slope in spring where and when individuals can form dense aggregations, likely in relation to larval extrusion behaviour (Fig. 10). Such patchy distribution is common for many fish species and well described for most small pelagic fishes, which assemble in dense schools of sometimes very large size (herring, sardines, anchovies, and others). It has also been reported for Sebastes species in the Pacific Ocean (Spencer et al. 2009).

Highly over-dispersed distribution poses particular challenges for surveys that are designed to estimate abundance or biomass, mainly because the uncertainty in these estimates increases as over-dispersion increases. In such situations, conventional survey designs display poor performance, i.e. results in high uncertainties. Adaptive survey design (Thompson and Seber 1996) has been suggested as an efficient solution to this problem. Recent examples can be found in Harbitz et al. (2009), Spencer et al. (2012) and Hanselman et al. (2012) who investigated adaptive acoustic survey designs for the abundance estimation of Atlantic herring and Alaskan rockfish. The result of such approach is to substantially reduce abundance/biomass uncertainties at a relatively low cost of increased observations intensity. Adaptive sampling schemes might efficiently improve any survey design for redfish on the shelves and slopes where patchy distributions are obvious. To date, such designs have not been investigated for Atlantic redfish surveys and uncertainties in abundance estimates are still poorly considered in survey planning and data analyses.

\section{Beyond single species surveys}

As seen from Sections 2, 3 and 8, beaked redfish occupies a wide range of depths, regions and habitats and therefore interacts with many components of the North Atlantic ecosystems. Monitoring of beaked redfish on shelves and slopes has generally been part of multispecies monitoring efforts (e.g. Anonymous 2010) but in the open oceanic basins of the North Atlantic, redfish surveys have been rather dissociated from the monitoring of other species or biological groups.

In the North Atlantic, the horizontal distribution of the mesopelagic layer (acoustically described as the deep scattering layer, DSL) overlaps with most of the distribution of pelagic S. mentella. Mesopelagic layers are ubiquitous features of the world ocean, and are believed to host up to 1 billion tons of fishes, 10 times the world's total annual fish catch (Gjøsæter and Kawaguchi 1980) in addition to many other groups (cephalopods, crustaceans, jellyfishes). The ecology within the mesopelagic layer is still largely unknown and fundamental questions such as the trophic importance of this deep layer for commercial fish species, higher in the water column, or for marine mammals as well as for the retention of material sedimenting from the upper layers are still unanswered. The degree of interannual or interdecadal variations in biomass and production is unknown, although this may strongly influence the dynamics of many fish and mammal predators. 
Current scientific investigations on redfish and on the mesopelagic layer are uncoupled, despite the fact that redfish in the open ocean is tightly coupled to this layer, as illustrated in Figure 7. Given appropriate adaptation of sampling strategies and observation methods, redfish surveys in the open North Atlantic Ocean have the potential to initiate and support ecological research and assessment with a much wider scope, within one of the least known but biological significant component of North Atlantic ecosystems.

\section{Summary and recommendations}

In the present contribution we have reviewed many aspects of biology, ecology and fishery that motivate and affect the way beaked redfish can be monitored in the North Atlantic. The key difficulties include the basin-wide geographical distribution, the occupation of demersal and benthic habitats at different stages of the life cycle, unknown recruitment controls, difficulties in ageing, species identification and stock identification, poorly described seasonal and ontogenetic large scale migrations, a deep distribution which imply remote access to hydroacoustic devices and difficulties to conduct tagging or diet studies, and generally poor knowledge of $S$. mentella interactions with the pelagic ecosystems of the Irminger and Norwegian Seas. Although this could appear as a bleak picture of the current state of the art in $S$. mentella monitoring, solutions exist for most of the above challenges and some have been tried in several instances. Future monitoring of $S$. mentella can therefore be achieved with higher success and could even serve as a pilot for a number of fish species displaying similar monitoring challenges. The recommendations below provide guidelines for the development of $S$. mentella monitoring in the future.

- Monitoring the entire distribution area of $S$. mentella in the North Atlantic requires sustained coordination effort by ICES and stronger international support than currently available. Assessing the state of the stocks of Sebastes mentella necessitates that its entire geographical and depth distribution area be surveyed (ICES 2011a). Given the very widespread geographical (>650000 $\mathrm{NM}^{2}$ ) and depth distribution (100-950 m) of the species, such monitoring requires dedicated international effort of at least 150 daysat-sea. Such extensive survey can be operated on a multiannual basis.

- Over shelf areas, surveys should consider the demersal and pelagic components of the populations, using combined trawl and hydro-acoustic surveys and appropriate survey designs. Because beaked redfish populations include pelagic and demersal components it is vital that trawl surveys be supplemented by simultaneous and synoptic acoustic registering and scrutinizing. It is also necessary to improve and harmonise the practice used to combine trawl swept-area estimates and acoustic estimates in order to derive total abundance estimate that are as accurate as possible, (see e.g., Aglen et al. 1997; Hjellvik et al. 2003, 2007). On the continental shelves and slopes, the spatial distribution of S. mentella is over dispersed, which may results in highly uncertain abundance estimates. Assessment of uncertainty and development of suitable sampling strategies such as adaptive sampling designs must be considered in the future.

- Efforts to standardise hydroacoustic interpretation methods and target strength equations should be pursued through dedicated international workshops. Differences in scrutinizing methods had a very large impact on the abundance estimate of redfish in the open ocean, and probably constitute the major source of uncertainty for any quantitative estimate. Complete descriptions of scrutinizing protocols as well as continuous and rigorous evaluation and cross-validation of scrutinizing techniques are needed to ensure the highest possible accuracy of hydroacoustic estimates of $S$. mentella abundance and distribution. Recent efforts towards the definition of common $T S$ equations (ICES 2010) must be pursued by conducting specific data acquisition at sea combined with new numerical analyses. This will help in obtaining precise $T S$ estimates and understand the factors modulating target strength (daynight cycles, developmental stages, regional differences, etc.). Hydroacoustic observations from hull mounted echosounders should be complemented by observations using deep-towed transducers.

- Reliable age determination and validation efforts should be pursued. These have been initiated in recent years (ICES 2006, 2009c). They should be combined with tagging and OTC marking of juvenile $S$. mentella otoliths.

- The reliability of species identification should be improved by internationally agreed procedures based on morphological and genetic identification techniques. Species identification based on morphological characteristics is uncertain and more difficult or even not possible for young and small individuals. Scientists and technicians working on Sebastes samples must keep a high level of training in morphological identification. This should always be supplemented by additional techniques based on genetic analysis either on genotype or phenotype. A protocol describing procedures and methods to use for diagnostic identification using DNA or electrophoresis techniques would constitute a significant advance for the identification of Sebastes species.

- Stock identification studies should be pursued and extended in areas where little work has been done up to present (e.g., Faroes, Norwegian and Barents Sea). Resolving the stock structure of S. mentella in the whole North Atlantic and identifying and quantifying the interactions between local populations remains a major challenge. A comprehensive genetic investigation and underwater tagging efforts in different areas will help solving this issue. Although extensive genetic studies have been conducted on the adult stock of deep-sea redfish in the Irminger Sea, little is known about the redfish (both juveniles and adults) inhabiting the continental shelf and slope of Greenland. In the Norwegian and Barents Seas only few genetic studies have been conducted and tagging has never been attempted. It is recommended that such studies be conducted.

- The Underwater Tagging Equipment (UTE) provides a unique opportunity to resolve key scientific issues and the use of the UTE should be promoted and supported 
internationally. Tagging programs using the UTE could significantly contribute to resolve key questions related to migration (Sect. 8), stock structure (Sect. 6), age determination (Sect. 7), recruitment (Sect. 5), habitat (Sect. 9) and diet (Sect. 14). It is recommended that international tagging surveys are conducted in the future. Current knowledge of the seasonal migration patterns of beaked redfish remains elusive and can be substantially improved by conducting more in situ tagging at depths of several hundred meters as conducted in the Irminger Sea until 2008. This effort should be initiated in the Norwegian and Barents Seas.

- Collection and analysis of appropriate hydrographic data should be pursued in the Irminger Sea and intensified in the Norwegian Sea. Recent analyses from WKREDOCE (ICES 2012c) confirm that the distribution of $S$. mentella is confined within the Altantic waters of the subpolar gyres in the Irminger and Norwegian Seas. However, the influence of varying ocean climate conditions on the seasonal and interannual changes in abundance and distribution of S. mentella remains largely unknown.

- Additional observations of the species community in the mesopelagic zone should be initiated. The biology and ecology of $S$. mentella is tightly coupled to the biological community of the mesopelagic zone, but the two things have not been studied jointly and very little is known of the basic properties of the fauna constitutive of the mesopelagic zone (productivity, species composition, year-to-year variability, etc.). S. mentella surveys constitute unique platforms to study the ecology of the mesopelagic zone. Such joint studies would provide the necessary data support the ecosystem approach to fisheries management in the deep pelagic ocean whilst improving trophic ecological studies of S. mentella.

Acknowledgements. B. Planque, K. Kristinsson and K. Nedreaas work was support by the project DEEPFISHMAN, EU-grant 227390. The authors are grateful to the ICES secretariat for providing support to the working group on redfish surveys, where the current work was initiated.

\section{References}

Aglen A., Engaas A., Huse I., Michalsen K., Stensholt B., 1997, Vertical distribution of cod, haddock and redfish; impact on bottom trawl and acoustic surveys in the Barents Sea. 7th Russian/Norwegian symposium: gear selection and sampling gears. Murmansk, Russia, PINRO, pp. 77-92.

Andriashev A.P., 1954, Fishes of the Northern Seas of the USSR. Moscow-Leningrad Academy of Science Press.

Anonymous, 2004, Population structure, reproductive strategies and demography of redfish (Genus Sebastes) in the Irminger Sea and adjacent waters (ICES V, XII and XIV, NAFO 1). REDFISH QLK5-CT1999-01222 Final Report.

Anonymous, 2009, Report of the NEAFC working group on collating information on the distribution of Sebastes mentella in ICES subareas I and II and distribution of catches from the stock. London, North East Atlantic Fisheries Commission.

Anonymous, 2010, Survey report from the joint Norwegian/Russian ecosystem survey in the Barents Sea in August-September 2009IMR/PINRO Joint Report Series, IMR/PINRO.
Armstrong J.D., Bagley P.M., Priede I.G., 1992, Tracking deepsea fish using ingestible transmitters and an autonomous seafloor instrument package. In: Priede I.G., Swift S.M. (Eds.), Wildlife telemetry remote monitoring and tracking of animals., Ellis Horwood limited, pp. 376-386.

Arnold G., Dewar H., 2000, Electronic tags in marine fisheries : a 30 -year perspective. Symposium on Tagging and tracking marine fish with electronic devices, Honolulu.

Cadrin S.X., Bernreuther M., Daníelsdóttir A.K., Hjörleifsson E., Johansen T., Kerr L., Kristinsson K., Mariani S., Nedreaas K., Pampoulie C., Planque B., Reinert J., Saborido-Rey F., Sigurdsson T., Stransky C., 2010, Population Structure of beaked redfish, Sebastes mentella: evidence of divergence associated with different habitats. ICES J. Mar. Sci. 67, 1617-1630.

Campana S.E., Zwanenburg K.C.T., Smith J.N., 1990, 210Pb/226Ra determination of longevity in redfish. Can. J. Fish. Aquat. Sci. 47, 163-165.

Dalen J., Nedreaas K., Pedersen R., 2003, A comparative acousticabundance estimation of pelagic redfish (Sebastes mentella) from hull-mounted and deep-towed acoustic systems. ICES J. Mar. Sci. $60,472-479$.

Drevetnyak K., Nedreaas K.H., 2009, Historical movement pattern of juvenile beaked redfish (Sebastes mentella Travin) in the Barents Sea as inferred from long-term research survey series. Mar. Biol. Res. 5, 86-100.

Drevetnyak K.V., Nedreaas K.H., Planque B., 2011, Chapter 5.7. Redfish. In: Jakobsen T., Ozhigin V.K. (Eds.), The Barents Sea - ecosystem, resources and management. Half a century of Russian-Norwegian cooperation, pp. 293-308.

Ermolchev V.A., 2009, Methods and results of in situ target-strength measurements of Atlantic cod (Gadus morhua) during combined trawl-acoustic surveys. ICES J. Mar. Sci. 66, 1225-1232.

Gauthier S., Rose G.A., 2001, Target strength of encaged Atlantic redfish (Sebastes spp.). ICES J. Mar. Sci. 58, 562-568.

Gjøsæter J., Kawaguchi K., 1980, A review of the world resources of mesopelagic fish. Rome, FAO.

González C., Bruno I., Paz X., 2000, Food and feeding of deep-sea redfish (Sebastes mentella Travin) in the North Atlantic. NAFO Sci. Counc. Stud. 33, 89-101.

Hanselman, D.H., Spencer, P., McKelvey, D.R., Martin, M.H., 2012, Application of an acoustic-trawl survey design to improve estimates of rockfish biomass. Fish. Bull. 110, 379-396.

Harbitz A., Ona E., Pennington M., 2009, The use of an adaptive acoustic-survey design to estimate the abundance of highly skewed fish populations. ICES J. Mar. Sci. 66, 1349-1354.

Hátún H., Payne M.R., Beaugrand G., Reid P.C., Sand $\varnothing$ A.B., Drange H., Hansen B., Jacobsen J.A., Bloch D., 2009, Large biogeographical shifts in the north-eastern Atlantic Ocean: From the subpolar gyre, via plankton, to blue whiting and pilot whales. Prog. Oceanogr. 80, 149-162.

Hislop J.R.G., 1969, Investigations by divers on the survival of tagged haddock. Underwater Association Report, 85-90.

Hjellvik V., Michalsen K., Aglen A., Nakken O., 2003, An attempt at estimating the effective fishing height of the bottom trawl using acoustic survey recordings. ICES J. Mar. Sci. 60, 967-979.

Hjellvik V., Tjøstheim D., Godø O.R., 2007, Can the precision of bottom trawl indices be increased by using simultaneously collected acoustic data? The Barents Sea experience. Can. J. Fish. Aquat. Sci. 64, 1390-1402.

Hureau J.-C., Litvinenko N.I., 1986, Scorpaenidae In: Whitehead P.J.P., Bauchot M.-L., Hureau J.-C., Nielsen J., Tortonese E. (Eds.), Fishes of the North-eastern Atlantic and the Mediterranean (FNAM). Paris, UNESCO, pp. 1211-1229. 
ICES, 2006, Report of the workshop on age determination of redfish (WKADR). ICES CM 2006/RMC:09, 43 p.

ICES, 2007. Report of the study group on redfish stocks (SGRS). ICES CM 2007/RMC:12.

ICES, 2008, Report of the Ad hoc group on the international redfish survey in the Norwegian Sea (AGRED). ICES CM 2008/ACOM: 63, $48 \mathrm{p}$.

ICES, 2009a, Report of the planning group on redfish surveys (PGRS). ICES CM 2009/RMC:08, 27 p.

ICES, 2009b, Report of the planning group on redfish surveys (PGRS). ICES CM 2009/RMC:05, 54 p.

ICES, 2009c, Report of the workshop on age determination of redfish (WKADR). ICES CM 2009/ACOM:57, 68 p.

ICES, 2009d, Report of the workshop on redfish stock structure (WKREDS). ICES CM 2009/ACOM:37, 67 p.

ICES, 2010, Report of workshop on the Determination of Acoustic Target Strength of Redfish (WKTAR). ICES CM 2010/SSGESST:15, 29 p.

ICES, 2011a, Beaked redfish (Sebastes mentella) in Subareas I and II. Advice June 2011. . ICES Advice 2011 Chapter 3.4.5, Book 3, pp. 34-41.

ICES, 2011b, Report of the North Western Working Group (NWWG). ICES CM ACOM: 07.

ICES, 2011c, Report of the working group on redfish surveys (WGRS). ICES CM 2011/SSGESST:21, 62 p.

ICES, 2012a, Report of the Arctic fisheries working group (AFWG). ICES CM 2012/ACOM:05, 633 p.

ICES, 2012b, Report of the benchmark workshop on redfish (WKRED). ICES CM 2012/ACOM: 48, 289 p.

ICES, 2012c, Report of the third Workshop on Redfish and Oceanographic Conditions (WKREDOCE-3). ICES CM 2012/ACOM:25, 66 p.

Johansen T., Dahle G., 2004, Discrimination among species of the genus Sebastes in the North Atlantic by random amplified polymorphic DNA. Sarsia 89, 478-483.

Jones R., 1979, Materials and methods used in marking experiments in fishery research. FAO Fish. Techn. Pap. 190, 134 p.

Kenchington T.J., 1986, Morphological comparison of two Northwest Atlantic redfishes, Sebastes fasciatus and S. mentella, and techniques for their identification. Can. J. Fish. Aquat. Sci. 43, 781-787.

Magnússon J., 1996, The deep scattering layers in the Irminger Sea. J. Fish Biol. 49, 182-191.

Magnússon J., Magnússon J.V., 1995, Oceanic redfish (Sebastes mentella) in the Irminger Sea and adjacent waters. Sci. Mar. 59, 241-254.

Makhrov A.A., Artamonova V.S., Popov V.I., Rolskiy A.Y., Bakay Y.I., 2011, Comment on: Cadrin et al. (2010) "Population structure of beaked redfish, Sebastes mentella: evidence of divergence associated with different habitats. ICES Journal of Marine Science, 67: 1617-1630". ICES J. Mar. Sci. 68, 2013-2015.

Mamylov V.S., 1999, Methodical aspects of trawl-acoustic surveys on redfish stock in the Irminger Sea. Working Document 3, Report of the study group on redfish stocks. ICES CM 1999/G:9.

Melnikov S.P., Pedchenko A.P., Shibanov, V.N., 2001, Results from the Russian investigations on pelagic redfish (Sebastes mentella, Travin) in the Irminger Sea and in NAFO Division 1F. NAFO SCR Doc. 01/20. Ser. No. N4388.

Misra R.K., Ni I.-H., 1983, Distinguishing beaked redfishes (deepwater redfish, Sebastes mentella and Labrador redfish, S. fasciatus) by discriminant analysis (with covariance) and multivariate analysis of covariance. Can. J. Fish. Aquat. Sci. 40, 1507-1511.
Nedreaas K., Johansen T., Nævdal G., 1994, Genetic studies of redfish (Sebastes spp.) from Icelandic and Greenland waters. ICES J. Mar. Sci. 51, 461-467.

Nedreaas K., Nævdal G., 1989, Studies of Northeast Atlantic species of redfish (genus Sebastes) by protein polymorphism. J. Cons. 46, 76-93.

Nedreaas K., Nævdal G., 1991a, Genetic studies of redfish (Sebastes spp.) along the continental slopes from Norway to East Greenland. ICES J. Mar. Sci. 48, 173-186.

Nedreaas K., Nævdal G., 1991b, Identification of 0- and 1-group refish (genus Sebastes) using electrophoresis. ICES J. Mar. Sci. 48, 91-99.

Ona E., Svellingen I., 2001, Target strength analysis in high fish densities using a probing split beam transducer. J Acoust. Soc. Am. $109,2305$.

Pedchenko A.P., 2005, The role of interannual environmental variations in the geographic range of spawning and feeding concentrations of redfish Sebastes mentella in the Irminger Sea. ICES J. Mar. Sci. 62, 1501-1510.

Pedersen G., Dalen J., Ona E., Nedreaas K., Pedersen R., 2005, In situ target strength measurement of pelagic Atlantic redfish (Sebastes mentella L.) using a acoustic deep-towed system. unpublished.

Petersen C.G.J., 1896, The yearly immigration of young plaice into the Limfiord from the German Sea. Rep. Dan. Biol. Stn. 6, pp. 5-84.

Pétursdóttir H., Gislason A., Falk-Petersen S., Hop H., Svavarsson J., 2008, Trophic interactions of the pelagic ecosystem over the Reykjanes Ridge as evaluated by fatty acid and stable isotope analyses. Deep Sea Res. II 55, 83-93.

Planque B., Bethke E., Drevetnyak K., Harbitz A., Nedreaas K., Pedchenko A.P., Pedersen R., Skúvadal F., Zubov V., 2009, Workshop on hydro-acoustic scrutinizing in the Norwegian Sea. Fisken og Havet. Bergen, Institute of Marine Research.

Planque B., Johannesen E., Drevetnyak K.V., Nedreaas K., 2012, Historical variations in the year-class strength of beaked redfish (Sebastes mentella) in the Barents Sea. ICES J. Mar. Sci. 69, 547-552.

Power D.J., Ni I.-H., 1985, Morphometric differences between golden redfish (Sebastes marinus) and beaked redfishes (S. mentella and S. fasciatus). J. Northw. Atl. Fish. Sci. 6, 1-7.

Priede I.G., Smith K.L., 1986, Behavior of the abyssal grenadier, Coryphaenoides yaquinae, monitored using ingestible acoustic transmitters in the Pacific Ocean. J. Fish Biol. 29, 199-206.

Reynisson P., Sigurðsson T., 1996, Diurnal variation in acoustic intensity and target-strength measurements of oceanic redfish (Sebastes mentella) in the Irminger Sea. ICES CM 1996/G:25, 15 p.

Rikhter V.A., 1996, On population structure of beaked redfish (Sebastes mentella Travin) in the Irminger Sea as related to larval drift. NAFO Sci.Counc.Stud. 27, 49-56.

Saborido-Rey F., 1994, The genus Sebastes Cuvier, 1829 (Pisces, Scorpaenidae) in the North Atlantic: identification of species and populations using morphometric methods; Growth and reproduction of the Flemish Cap populations. Madrid, University of Madrid.

Saborido-Rey F., Garabana D., Cervino S., 2004, Age and growth of redfish (Sebastes marinus, S. mentella, and S. fasciatus) on the Flemish Cap (Northwest Atlantic). ICES J. Mar. Sci. 61, 231-242.

Schauer J., Hissmann K., Fricke H., 1997, A method for deployment of externally attached sonic fish tags from a manned submersible and their effects on coelacanths. Mar. Biol. 128, 359-362. 
Sigurðsson T., Kristinsson K., Ratz H.J., Nedreaas K.H., Melnikov S.P., Reinert J., 2006a, The fishery for pelagic redfish (Sebastes mentella) in the Irminger Sea and adjacent waters. ICES J. Mar. Sci. 63, 725-736.

Sigurðsson T., Thorsteinsson V., Gustafsson L., 2006b, In situ tagging of deep-sea redfish: application of an underwater, fish-tagging system. ICES J. Mar. Sci. 63, 523-531.

Spencer P., Hanselman D., McKelvey D., 2009, Trawl survey designs for reducing uncertainty in biomass estimates for patchilydistributed species. ICES CM 2009/N:05, 16 p.

Spencer P., Hanselman, D.H., McKelvey D.R., 2012, Simulation modeling of a trawl-acoustic survey design for patchily distributed species. Fish. Res. 126, 289-299.

St. Pierre J.F., de la Fontaine Y., 1995, Fecundity and reproduction characteristics of beaked redfish (Sebastes fasciatus and S. mentella) in the Gulf of St. Lawrence. Can. Techn. Rep. Fish. Aquat. Sci. 2059.
Stransky C., 2000, Migration of juvenile deep-sea redfish (Sebastes mentella Travin) from the East Greenland shelf into the central Irminger Sea. ICES CM 2000/N:28, 10 p.

Stransky C., Kanisch G., Krüger A., Purkl S., 2005, Radiometric age validation of golden redfish (Sebastes marinus) and deepsea redfish (S. mentella) in the Northeast Atlantic. Fish. Res. 74, 186-197.

Templeman W., 1959, Redfish distribution in the North Atlantic. Bull. Fish. Res. Board Can. 120, 120-173.

Thompson S.K., Seber G.A.F., 1996, Adaptive sampling. New York, Wiley. Wiley series in probability and statistics.

Treble M.A., Campana S.E., Wastle R.J., Jones C.M., Boje J., 2008, Growth analysis and age validation of a deepwater Arctic fish, the Greenland halibut (Reinhardtius hippoglossoides). Can. J. Fish. Aquat. Sci. 65, 1047-1059. 